\title{
甘肃小苏干湖盐沼湿地盐地风毛菊叶形态-光合生 理特征对淹水的响应
}

\section{李 群 赵成章* 王继伟 文 军李子琴 马俊逸}

西北师范大学地理与环境科学学院, 甘肃省湿地资源保护与产业发展工程研究中心, 兰州 730070

\begin{abstract}
摘 要 盐沼湿地植物叶片功能性状对淹水的响应分析, 有助于探究植物叶片可塑性机制与光合生理特征间的内在关联性, 对深入理解盐沼湿地植物的生境抗逆性策略具有重要意义。根据小苏干湖湖水泛滥区静水持留时间长短分别设置: 轻度淹水 区(静水持留30-90天)、中度淹水区(静水持留90-150天)、重度淹水区(静水持留150-210天) 3 个试验样地，以盐地风毛菊 (Saussurea salsa) 为研究对象, 研究了小苏干湖盐沼湿地盐地风毛菊叶片功能性状对淹水的响应。结果表明: 随着静水持留时 间的增加, 轻度淹水区盐地风毛菊形态上采用小比叶面积 $(S L A)$ 的肉质化小叶模式, 光合生理上具有高实际光合效率 $(Y(I I))$ 和 低调节性能量耗散的量子产额 $(Y(N P Q))$ 的协同变异; 重度淹水区盐地风毛菊形态和光合生理上则采用与轻度淹水区完全相 反的协同变异策略; 在 3 个样地中, $S L A$ 与 $Y(I)$ 、光化学淬灭 $(Q P)$ 和 $Y(N P Q)$ 间均呈极显著相关关系; 叶绿素 $\mathrm{a}$ 含量和叶绿素 $\mathrm{b}$ 含 量与调节性能量耗散的量子产额 $(Y(N O))$ 均呈显著正相关关系。小苏干湖湖水泛滥区静水时空演变格局影响下, 盐地风毛菊种 群通过改变叶面积、叶厚度和 $S L A$ 等叶片形态特征, 适时调整叶片 $Y(I)$ 和 $Y(N P Q)$ 等光合生理特征, 实现植物叶片光合碳同化 产物的收支平衡, 表现出对水盐异质性环境较强的耐受性, 反映了盐沼湿地植物在极端生存环境下的叶片可塑性和抗逆性机 制。
\end{abstract}

关键词＼cjkstart叶性状; 比叶面积; 实际光化学效率; 风毛菊; 小苏干湖

李群, 赵成章, 王继伟, 文军, 李子琴, 马俊逸 (2019). 甘肃小苏干湖盐沼湿地盐地风毛菊叶形态-光合生理特征对淹水的响应. 植物生态学报, 43, 685-696. DOI: $10.17521 /$ cjpe.2019.0132

\section{Morphological and photosynthetic physiological characteristics of Saussurea salsa in response to flooding in salt marshes of Xiao Sugan Lake, Gansu, China}

LI Qun, ZHAO Cheng-Zhang ${ }^{*}$, WANG Ji-Wei, WEN Jun, LI Zi-Qin, and MA Jun-Yi

College of Geography and Environmental Science, Northwest Normal University, Research Center of Wetland Resources Protection and Industrial Development Engineering of Gansu Province, Lanzhou 730070, China

\section{Abstract}

Aims The response of plant leaf functional traits to flooding in salt marshes is not only helpful in exploring the internal correlation between leaf plasticity mechanism and photosynthetic characteristics, but also of vital significance for gaining a better understanding on the stress resistance strategies of plants in salt marsh wetlands. The aim of this study is to investigate the responses of leaf functional traits of Saussurea salsa to flooding with the changes of water-logging durations.

Methods The research site was located in provincial migratory bird nature reserve in Xiao Sugan Lake, Gansu Province, China $\left(39.22^{\circ}-39.35^{\circ} \mathrm{N}, 94.45^{\circ}-94.59^{\circ} \mathrm{E}\right)$. A sample belt was selected from the edge of the lakeshore to the end of the perennial tidewater line in the low-lying area along the north side of Xiao Sugan River. The duration of water-logging in the salt marsh wetland was measured base on the water level marked by the flood rise and retreat marks in Xiao Sugan Lake over the years. The sample belt was divided into 3 plots according to the water-logging duration: low flooding area (water-logging duration: 30-90 days); medium flooding area (waterlogging duration: 90-150 days); and deep flooding area (water-logging duration: 150-210 days). Six subplots $(2 \mathrm{~m} \times 2 \mathrm{~m})$ of $S$. salsa were selected from each of the three plots for a total of 18 subplots. We investigated community characteristics and population traits of $S$. salsa, soil moisture and soil electrical conductivity (EC). Six 
plants per subplot were selected for photosynthesis and chlorophyll fluorescence measurements. Foliar samples collected from each of the six $S$. salsa were taken to the laboratory for measurements of leaf traits (leaf area, thickness, dry mass and chlorophyll content).

Important findings The results showed that $S$. salsa changed the covariation strategy of $S$. salsa foliar morphology and photosynthesis with the extension of water-logging duration. In the low flooding area, $S$. salsa adopted fleshy lobular pattern with small specific leaf area $(S L A)$, high effective quantum yield of photosynthetic system II (PSII) photochemistry in light $(Y(I I))$ and low quantum yield of regulated energy dissipation $(Y(N P Q))$. However, $S$. salsa grew in the deep flooding area adopted completely opposite covariation strategy in foliar morphology and photosynthesis compared with those grew in the low flooding area. We observed a significant correlation between $S L A$ and $Y(I I)$, photochemical quenching $(Q P)$, and $Y(N P Q)$, as well as a significant positive correlation between the quantum yield of non-regulated energy dissipation $(Y(N O))$ and chlorophyll a content $\left(C_{\mathrm{a}}\right)$, chlorophyll $\mathrm{b}$ content $\left(C_{\mathrm{b}}\right)$ in all of the three plots. Under the influence of the spatio-temporal evolution pattern of still water in the flooded area of Xiao Sugan Lake, $S$. salsa population achieved the balance of the photosynthetic carbon budget by changing the morphological characteristics of leaves, such as leaf area, leaf thickness and SLA, timely adjusting the photosynthetic characteristics, such as $Y(N P Q)$ and $Y(I I)$. Saussurea salsa showed strong tolerance to water and salt heterogeneity, reflecting the leaf plasticity and resistance mechanism of salt marsh wetland plant under extreme environments.

Key words leaf traits; specific leaf area; actual photochemical efficiency of PSII; Saussurea salsa; Xiao Sugan Lake

Li Q, Zhao CZ, Wang JW, Wen J, Li ZQ, Ma JY (2019). Morphological and photosynthetic physiological characteristics of Saussurea salsa in response to flooding in salt marshes of Xiao Sugan Lake, Gansu, China. Chinese Journal of Plant Ecology, 43, 685-696. DOI: 10.17521/cjpe.2019.0132

植物是一个功能和结构平衡的生命体, 在长期 的进化和自然选择过程中, 植物通过调整内在和外 在形态结构优化其功能和生理代谢过程以适应周围 环境变迁(Brodribb \& Jordan, 2011; Gong et al., 2011)。叶片是植物能量和物质转化的重要场所, 叶 片的结构性状在一定程度上决定叶片光合生理活性, 能够反映植物叶片对所吸收光能的利用水平(金鹰 和王传宽, 2015)。叶绿素苂光与叶片的光合作用密 切相关(Liu et al., 2018), 是光合作用的探针, 任何 环境因子对光合作用的影响都可以通过光系统II (PSII) 叶绿素苂光量子效率的变化快速、灵敏且无损 伤地反映出来(Maxwell \& Johnson, 2000; 柏新富等, $2012)$ 。叶面积 $(L A)$ 、叶厚度 $(L T)$ 和比叶面积 $(S L A)$ 等影响着叶片的水分供应、存储以及光合速率 (Scoffoni et al., 2011; Ogburn \& Edwards, 2012), 与 植物的光拦截效率、蒸腾速率等密切相关(Milla \& Reich, 2007; 李群等, 2018)。在盐胁迫下, 植物往往 会形成小而厚、低SLA的肉质化叶片, 发育大量咜水 组织、输水组织和栅栏组织, 使植物免受盐离子毒 害、缓解盐胁迫的同时, 减少水分散失以增加蒸腾 效率(赵可夫等, 2013), 容纳更多的叶绿体, 增加叶 绿体对光照及 $\mathrm{CO}_{2}$ 的吸收面, 提高叶片的电子传递 速率 $(E T R)$ 和光合效率(王艺和韦小丽, 2010; 魏志
刚和王玉成, 2015); 而水淹条件下，植物则会通过 增加叶面积, 扩大空气接触面, 提高对厌氧环境的 耐受性(van den Brink et al., 1995)。植物对水淹、盐 分的耐受性和抗逆性是植物长期适应极端环境的结 果, 土壤渍水即淹水是影响生态系统稳定性的因子 之一(Gimeno et al., 2012)。内陆盐沼湿地由于其特 殊的水源供给和静水时空演变格局的差异性, 使湿 地植物群落内部形成特殊的土壤水盐分配格局, 改 变了种群内每个植株可获得的资源数量, 迫使植株 叶片在外在形态和内在生理特征方面协同变异形成 适应胁迫生境的功能性状组合, 实现植物在光合碳 同化产物积累与耗散间的平衡, 从而提高对严酷生 境的抗逆性和耐受性(di Bella et al., 2014; Wang et al., 2018)。因此, 研究叶片形态性状和光合生理特 征对淹水梯度的响应, 有助于深入了解盐沼湿地植 物的抗逆性和耐受性, 对于探索盐沼湿地植物表型 可塑性和碳同化机制有重要意义。

盐地风毛菊(Saussurea salsa) 为菊科风毛菊属 的稀盐盐生植物, 分布于高海拔的盐土草地、戈壁 滩及湖边等地区, 是我国西北内陆盐沼湿地的主要 植物。目前, 围绕盐渍对植物不同生长部位的影响 和植物对外来干扰的耐受性和抗逆性(di Bella et al., 2014; Wang et al., 2018)、盐沼湿地植物SLA和PSII

www.plant-ecology.com 
热耗散对土壤水分的响应(李群等, 2017)、干旱和水 分胁迫对植物光合效率的影响(Gao et al., 2017; 张 海燕等, 2018)等方面已有不少研究; 有关风毛菊繁 殖分配与海拔高度的相关性(王一峰等, 2012)、叶片 PSII光化学效率和光合色素对胁迫生境适应机制 (师生波等, 2012)的研究也得到了重视, 但是有关内 陆盐沼湿地静水时空演变格局差异条件下盐生植物 叶片功能性状对淹水的响应及其生态适应性尚不明 晰。鉴于此, 本研究以小苏干湖内陆盐沼湿地主要 稀盐盐生植物盐地风毛菊为研究对象, 通过研究盐 地风毛菊叶片形态性状与光合生理特征对淹水梯度 的响应, 试图明晰：(1)在淹水条件下, 盐地风毛菊 叶片形态性状与光合生理特征如何协同变异适应淹 水环境? (2)形成这种协同适应机制的原因有哪 些? 以加深对内陆盐沼湿地植物叶形态的生态适应 策略与光合作用机理的认识和理解。

\section{1 材料和方法}

\section{1 研究区域和样地概况}

研究区位于甘肃省酒泉市阿克塞县小苏干湖省 级候鸟自然保护区, 处于青藏高原柴达木盆地北缘 阿尔金山、党河南山与赛什腾山之间的花海子高原 盆地 $\left(39.22^{\circ}-39.35^{\circ} \mathrm{N}, 94.45^{\circ}-94.59^{\circ} \mathrm{E}\right)$, 海拔 2807-2 $808 \mathrm{~m}$ 。属内陆高寒半干旱气候, 年平均气 温 $2.0{ }^{\circ} \mathrm{C}$, 年降水量 $77.6 \mathrm{~mm}$, 蒸发量 $1964.8 \mathrm{~mm}$, 年日照时间 3 100-3 500 h, 大风天气盛行, 沙尘暴 发生频率高, 干燥度 30 , 无霜期 90 天左右。苏干湖水 系属于柴达木内流水系中西北端的一个独立水系, 发源于党河南山的大、小哈儿腾河出山口潜流于地 下, 在海子盆地成泉涌露, 汇成河网, 流入大苏干 湖和小苏干湖, 最终消耗于泉水溢出带的蒸发蒸腾 和湖面蒸发。土壤主要以草甸土、草甸沼泽土以及 盐碱土为主, 主要植物有: 盐地风毛菊、芦苇 (Phragmites australis) 、菆茂草 (Achnatherum splendens)、水麦冬(Triglochin palustris)、海非菜 (Triglochin maritima)、碱蓬(Suaeda glauca)、华扁穗 草 (Blysmus sinocompressus)、盐角草 (Salicornia europaea) 和冰草(Agropyron cristatum), 湖水泛滥区 植被呈现环带状分布。

\section{2 实验方法}

\subsection{1 实验设置}

小苏干湖是一个具有出口的微咸水湖, 湖周围
盐沼湿地的水淹频率每年1次，每年11月至次年4月 湿地表面有静水持留，5月湖水逐渐消退，其他时间 湿地暴露在空气中，根据苏干湖自然保护区20多年 来的水文记录, 湖水泛滥区宽度650-715 m。为便于 实验调查研究, 首先在小苏干湖北边地势平缓区域 从湖岸边缘向多年的潮水线末端布置 1 条宽 $50 \mathrm{~m}$, 长300 $\mathrm{m}$ 的样带, 该样带盐地风毛菊(生长期: 5 月上 旬至 8 月上旬, 90 天)为湿地群落的优势种; 然后按 照小苏干湖历年洪水涨退痕迹标记的水位线, 测算 盐沼湿地静水持留时长, 将该样带划分为 3 个样地 (图1), 分别如下: 1) 样地 $\mathrm{I}$ 为轻度淹水区(静水持留时 间: 当年11月下旬至次年2月上旬，60-90天)，离湖 水区150-300 m, 土壤表层明显有盐碱累积, 植被 呈聚集片状分布, 植被低矮, 密度较大, 主要植物 有盐地风毛菊、海乳草(Glaux maritima)、早熟禾(Poa pratensis) 和盐角草等; 2)样地 II 为中度淹水区(静水 持留时间：当年11月下旬至次年4月上旬，90-150 天), 离湖水区50-150 m, 土壤表层有盐碱累积, 植 被呈斑块状分布, 盐地风毛菊和海乳草相伴生长; 3) 样地III为重度淹水区 (静水持留时间: 当年11月下 旬至次年6月上旬，150-210天), 离湖水区 $0-50 \mathrm{~m}$, 土壤表层无盐碱累计, 土壤水分几乎一年中所有时 间均处于饱和状态, 主要植物有盐地风毛菊、海非 菜和赖草(Leymus secalinus)等。

\subsection{2 数据采集}

2018年8月17-25日，选择天气晴朗、土壤水盐 状况相对稳定的期间进行取样。首先, 在选定的 3 个 样地中按已划分的梯度, 从轻度淹水区到重度淹水 区依次设置 6 个 $2 \mathrm{~m} \times 2 \mathrm{~m}$ 样方, 总计 18 个样方; 接 着分别测定每个样方内湿地群落所有植物的高度、 盖度和密度; 然后在每一个样方中随机选择 6 株盐 地风毛菊(株高为大、中、小各 2 株), 用卷尺测量从 基部到最高分枝的高度, 定为株高; 接着选取每个 植株最外层 4 个方位充分伸展且健康完整的2-3个叶 片, 用于盐地风毛菊叶片光合特征和叶性状的调查; 最后齐地刈割每个样方地上所有植株带回实验室, 于 $80{ }^{\circ} \mathrm{C}$ 烘箱中烘干 $48 \mathrm{~h}$, 测量每个样地的地上生物 量。

1.2.2.1 光合特征值测定 选择晴朗天气的9:0012:00对标记过的盐地风毛菊进行植物气体交换等 参数的测定, 光合测定使用GFS-3000便携式光合测 量系统(Heinz Walz GmbH, Bavaria, Germany), 测量 


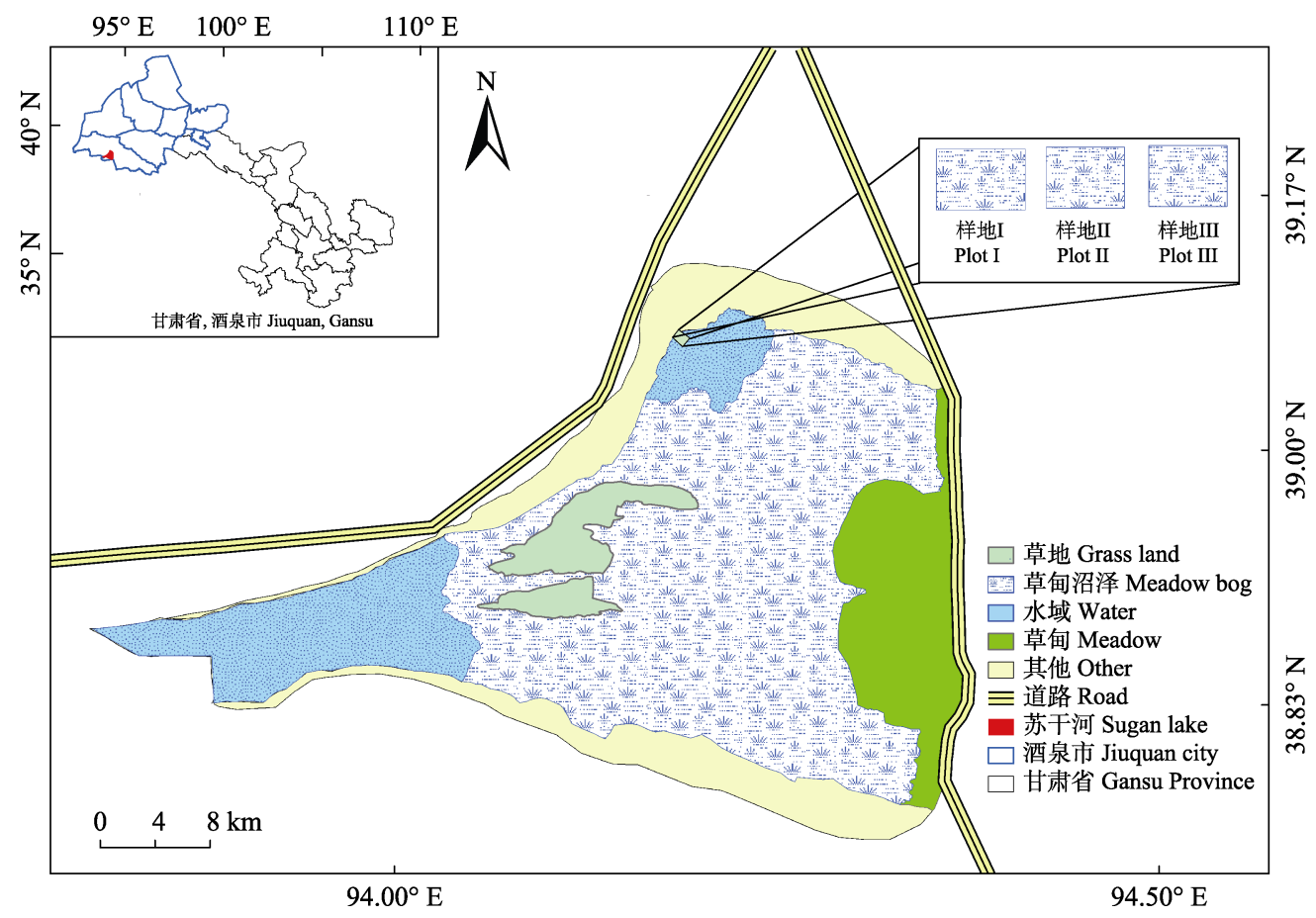

图1 小苏干湖盐沼湿地样地设置图。

Fig. 1 Locations of measured plots in salt marshes of Xiao Sugan Lake.

过程中使用人工红蓝光源, 光合有效辐射 $(P A R)$ 为 $1200 \mu \mathrm{mol} \cdot \mathrm{m}^{-2} \cdot \mathrm{s}^{-1}, \mathrm{CO}_{2}$ 浓度约为 $340 \mu \mathrm{mol} \cdot \mathrm{mol}^{-1}$, 流速设定为 $750 \mu \mathrm{mol} \cdot \mathrm{s}^{-1}$, 相对湿度 $(R H)$ 保持在 $60 \%-70 \%$, 叶片温度 $\left(T_{\text {leaf }}\right)$ 保持在 $15-20{ }^{\circ} \mathrm{C}$ 。选取每 个植株中端展开的 4 片成熟健康叶片分别测定叶片 的净光合速率 $\left(P_{\mathrm{n}}\right)$ 、蒸腾速率 $\left(T_{\mathrm{r}}\right)$ 等参数, 待数据稳 定后读取数据, 计算水分利用效率 $(W U E)=$ $\left(P_{\mathrm{n}} / T_{\mathrm{r}}\right)$ (李群等, 2017)。

1.2.2.2 LA、 LT 和SLA测定 将测定光合作用的叶 片装入信封迅速带回实验室, 用便携式激光叶面积 仪(CI-202, Walz, Camas, USA)扫描每个叶片, 利用 Image软件计算扫描的单叶叶面积; 使用游标卡尺 测量叶片厚度(精确到 $0.01 \mathrm{~mm}$ ), 测量时避开叶脉, 并尽量选择叶片中心部位, 每个叶片在不同部位测 量 5 次, 取平均值为该叶片的厚度; 最后将叶片装 入信封, 于 $80{ }^{\circ} \mathrm{C}$ 烘箱中烘干 $48 \mathrm{~h}$, 称质量即叶干质 量(精度0.000 $1 \mathrm{~g}$ ); SLA 用 $L A$ 和叶干质量的比值表 示。

1.2.2.3 光合色素含量测定 参考王学奎(2006)的 方法: 首先称取 $0.2 \mathrm{~g}$ 烘干的叶片, 洗净擦干, 去中 脉, 剪碎后放入研钵中, 加少量石英砂和碳酸钻粉 及2-3 mL 80\%的丙酮, 研磨至组织变白, 再加丙酮 $10 \mathrm{~mL}$, 研成匀浆, 暗处静置约 $10 \mathrm{~min}$; 然后将提取 液过滤并用丙酮定容至 $20 \mathrm{~mL}$ 试管中, 摇匀, 保存
于暗处 $24 \mathrm{~h}$ 待测, 每个样品3次重复; 最后将色素提 取液倒入比色典中, 以 $80 \%$ 丙酮作为空白对照, 分 别在波长663、646和 $470 \mathrm{~nm}$ 分光光度计下测定吸光 度 $(A 663 、 A 646$ 和 $A 470$ 分别表示在 3 个波长下的吸光 值)。依据朗伯比尔定律, 用公式计算提取液中各色 素的含量, 式中 $C_{\mathrm{a}} 、 C_{\mathrm{b}}$ 和 $C_{\mathrm{car}}$ 分别为叶绿素 $\mathrm{a} 、 \mathrm{~b}$ 及叶 黄素含量 $\left(\mathrm{mg} \cdot \mathrm{L}^{-1}\right)$; 再按下式求算植物组织中单位 干质量各色素的含量 $\left(\mathrm{mg} \cdot \mathrm{g}^{-1}\right)$ :

$$
\begin{aligned}
& C_{\mathrm{a}}=12.21 \times A 663-2.81 \times A 646 \\
& C_{\mathrm{b}}=20.13 \times A 646-5.03 \times A 663 \\
& C_{\mathrm{car}}=\left(1000 \times A 470-3.27 C_{\mathrm{a}}-104 C_{\mathrm{b}}\right) / 229
\end{aligned}
$$

植物组织中单位干质量各色素的含量 $\left(\mathrm{mg} \cdot \mathrm{g}^{-1}\right)$ $=$ 色素浓度 $\left(\mathrm{mg} \cdot \mathrm{L}^{-1}\right) \times$ 提取液体积 $(\mathrm{L}) \times$ 稀释倍数 $/$ 样 品干质量 $(\mathrm{g})$

1.2.2.4 土壤含水量测定 在湿地群落学调查样方 内随机挖掘 $1 \mathrm{~m} \times 1 \mathrm{~m} \times 0.5 \mathrm{~m}$ 土壤剖面, 用环刀 $\left(200 \mathrm{~cm}^{3}\right)$ 分 5 层间隔 $10 \mathrm{~cm}$ 采取土样, 重复 3 次, 现场 编号; 各土层均匀混合称鲜质量, 然后带回实验室 在 $105{ }^{\circ} \mathrm{C}$ 的烘箱内烘 $12 \mathrm{~h}$, 取出称质量, 计算出各 样地 $0-50 \mathrm{~cm}$ 土层土壤质量含水量。

1.2.2.5 土壤盐分测定 用电导法测定土壤含盐量 (张雅琼等, 2010), 采用上海雷磁仪器厂生产的 DDS-11C 便携式电导仪测浸出液的电导率, 3 次重复, 取平均值(李群等, 2017)。 
1.2.2.6 叶绿素荧光参数测定采用调制式 IMAGING-PAM叶绿素荧光仪(Heinz Walz GmbH, Effeltrich, Germany)现场测定各样地盐地风毛菊叶 片的叶绿素苂光参数(李群等, 2017), 参考Schreiber 等(1994)和Schreiber (2004)的方法计算相关参数:

光化学淬灭 $(Q P)=\left(F_{\mathrm{m}}{ }^{\prime}-F_{\mathrm{s}}\right) / F_{\mathrm{v}}{ }^{\prime}=1-\left(F_{s}-\right.$

$$
\left.F_{\mathrm{o}}{ }^{\prime}\right) /\left(F_{\mathrm{m}}{ }^{\prime}-F_{\mathrm{o}}{ }^{\prime}\right)
$$

非光化学淬灭 $(N P Q)=\left(F_{\mathrm{m}}-F_{\mathrm{m}}{ }^{\prime}\right) / F_{\mathrm{m}}{ }^{\prime}=F_{\mathrm{m}} / F_{\mathrm{m}}{ }^{\prime}$

$$
-1
$$

PSII实际光合效率 $Y(I I)=\Phi P S I I=\left(F_{\mathrm{m}}{ }^{\prime}-F_{\mathrm{t}}\right) / F_{\mathrm{m}}{ }^{\prime}$

PSII非调节性能量耗散的量子产量 $Y(N O)=$ $1 /\left(N P Q+1+q L\left(F_{\mathrm{m}} / F_{\mathrm{o}}-1\right)\right)$

PSII调节性能量耗散的量子产量 $Y(N P Q)=1-$ $Y(I I)-Y(N O)$

电子传递速率 $(E T R)=0.5 \times Y(I I) \times P A R \times 0.84$

式中, $F_{\mathrm{m}}{ }^{\prime}$ 为光下最大荧光; $F_{\mathrm{o}}{ }^{\prime}$ 为光下最小荧光; $F_{\mathrm{v}}{ }^{\prime}$ 为饱和脉冲光导致的苂光产额; $F_{\mathrm{s}}$ 为稳态荧光; $F_{\mathrm{t}}$ 为 实时苂光; $q L$ 为基于 “湖泊模型”的光化学淬灭系数; $P A R$ 为光合有效辐射。

\section{3 数据处理}

基于野外调查和室内实验获取的植物功能性状
和生长环境数据库, 首先使用软件 CANOCO 4.5 对 环境和植被功能性状进行除趋势典范对应分析 (DCCA)排序和午余分析(RDA)确定关键限制环境 因子及对环境因子响应最显著的功能性状变量; 其 次通过R 3.6.1软件进行协方差分析剔除协变量的影 响, 确定与实验设计最相关的变量; 最后采用SPSS 22.0 软件进行相关分析和单因素方差分析 (ANOVA)。通过Excel 2016和SigmaPlot 10.0软件绘 图。文中常用参数及其缩写见表1。

\section{2 结果和分析}

\section{1 盐沼湿地植物群落和盐地风毛菊种群生物学 特征及土壤理化性质}

各样地植物群落和盐地风毛菊种群生物学特征 及土壤理化性质的变化显著(表2)。土壤含水量 $(S M C)$ 和土壤电导率 $(E C)$ 在 3 个观测样地中存在显著差异 $(p<0.05)$ (表2), 从样地I到样地III, $S M C$ 增加了 0.88 倍, $E C$ 减少了 $61.27 \%$; 随着 $S M C$ 的逐渐增加和 $E C$ 的 逐渐减小, 湿地群落的高度随之增加, 增加了 4.01 倍，地上生物量 $(A B)$ 随之减少，减少了 $72.31 \%$; 盐 地风毛菊种群的高度呈增加趋势, 增加了 2.05 倍, 密度呈先增加后减少的趋势, 整体增加了 0.05 倍。表 明随着静水持留时间的增加和地表盐碱累积的减弱,

表1 文中常用参数及其缩写

\begin{tabular}{|c|c|c|}
\hline 参数 Parameter & 缩写 Abbreviation & 单位 Unit \\
\hline 土壤含水量 Soil moisture content & $S M C$ & $\%$ \\
\hline 土壤电导率 Soil electrical conductivity & $E C$ & $\mathrm{~ms} \cdot \mathrm{cm}^{-1}$ \\
\hline 地上生物量 Aboveground biomass & $A B$ & $\mathrm{~g} \cdot \mathrm{m}^{-2}$ \\
\hline 平均高度 Average height & $A H$ & $\mathrm{~cm}$ \\
\hline 密度 Density & $D$ & 株· $\mathrm{m}^{-2}$ \\
\hline 叶面积 Leaf area & $L A$ & $\mathrm{~cm}^{2}$ \\
\hline 叶厚度 Leaf thickness & $L T$ & $\mathrm{~mm}$ \\
\hline 比叶面积 Specific leaf area & $S L A$ & $\mathrm{~cm}^{2} \cdot \mathrm{g}^{-1}$ \\
\hline 叶干质量 Leaf dry mass & $L D W$ & $\mathrm{~g}$ \\
\hline 叶绿素a含量 Chlorophyll a content & $C_{\mathrm{a}}$ & $\mathrm{mg} \cdot \mathrm{g}^{-1}$ \\
\hline 叶绿素b含量 Chlorophyll b content & $C_{\mathrm{b}}$ & $\mathrm{mg} \cdot \mathrm{g}^{-1}$ \\
\hline 类胡萝卜素含量 Carotenoid content & $C_{\text {car }}$ & $\mathrm{mg} \cdot \mathrm{g}^{-1}$ \\
\hline 净光合速率 Net photosynthetic rate & $P_{\mathrm{n}}$ & $\mu \mathrm{mol} \mathrm{CO} 2 \cdot \mathrm{m}^{-2} \cdot \mathrm{s}^{-1}$ \\
\hline 蒸腾速率 Transpiration rate & $T_{\mathrm{r}}$ & $\mathrm{mmol} \mathrm{H}_{2} \mathrm{O} \cdot \mathrm{m}^{-2} \cdot \mathrm{s}^{-1}$ \\
\hline 水分利用效率 Water use efficiency & $W U E$ & $\mu \mathrm{mol} \mathrm{CO} \cdot \mathrm{mmol}^{-1} \mathrm{H}_{2} \mathrm{O}$ \\
\hline 实际光合效率 The actual photochemical efficiency of PSII & $Y(I I)$ & 无纲量 No dimension \\
\hline 非调节性能量耗散的量子产量 The quantum yield of non-regulated energy dissipation & $Y(N O)$ & 无纲量 No dimension \\
\hline 调节性能量耗散的量子产额 The quantum yield of regulated energy dissipation & $Y(N P Q)$ & 无纲量 No dimension \\
\hline 光化学淬灭系数 Photochemical quenching & $Q P$ & 无纲量 No dimension \\
\hline 非光化学猝灭系数 Non- Photochemical quenching & $N P Q$ & 无纲量 No dimension \\
\hline 电子传递速率 Electron transport rate & ETR & $\mu \mathrm{mol} \cdot \mathrm{m}^{-2} \cdot \mathrm{s}^{-1}$ \\
\hline
\end{tabular}

Table 1 The parameters and their abbreviations used in this paper. 
表2小苏干湖盐沼湿地土壤特性、群落生物学特征和盐地风毛菊种群特征(平均值土标准误差)

Table 2 Soil characteristics, biological characteristics of wetland community and population characteristics of Saussurea salsa in salt marshes of Xiao Sugan Lake $($ mean $\pm S E)$

\begin{tabular}{|c|c|c|c|c|c|c|}
\hline \multirow[t]{2}{*}{ 样地 Plot } & \multicolumn{4}{|c|}{ 群落特征 Community characteristics } & \multicolumn{2}{|c|}{ 盐地风毛菊 Saussurea salsa } \\
\hline & $S M C(\%)$ & $E C\left(\mathrm{~ms} \cdot \mathrm{cm}^{-1}\right)$ & $A H(\mathrm{~cm})$ & $A B\left(\mathrm{~g} \cdot \mathrm{m}^{-2}\right)$ & $A H(\mathrm{~cm})$ & $D\left(\right.$ 株· $\left.\mathrm{m}^{-2}\right)$ \\
\hline I & $31.79 \pm 1.59^{\mathrm{c}}$ & $9.94 \pm 0.50^{\mathrm{a}}$ & $6.16 \pm 0.31^{\mathrm{c}}$ & $165.30 \pm 8.27^{\mathrm{a}}$ & $7.48 \pm 0.37^{\mathrm{b}}$ & $59 \pm 2.95^{\mathrm{c}}$ \\
\hline II & $39.12 \pm 1.96^{\mathrm{b}}$ & $7.52 \pm 0.30^{\mathrm{b}}$ & $9.73 \pm 0.49^{b}$ & $121.66 \pm 6.08^{b}$ & $13.8 \pm 0.69^{\mathrm{b}}$ & $74 \pm 3.70^{\mathrm{a}}$ \\
\hline III & $59.63 \pm 2.98^{\mathrm{a}}$ & $3.85 \pm 0.19^{\mathrm{c}}$ & $30.88 \pm 1.54^{\mathrm{a}}$ & $95.93 \pm 4.80^{\mathrm{c}}$ & $22.8 \pm 1.14^{\mathrm{a}}$ & $62 \pm 3.10^{\mathrm{b}}$ \\
\hline
\end{tabular}

同列不同小写字母表示样地间差异显著 $(p<0.05)$ 。 $A B 、 A H 、 D 、 E C 、 S M C$ 同表1。

Different lowercase letters in the same column indicate significant differences among plots $(p<0.05)$. $A B, A H, D, E C, S M C$ see Table 1 .

群落内部植物生长环境胁迫得以改善, 有利于植被 高度的增加, 但不利于植物地上生物量的积累; 盐地 风毛菊的高度有所增加, 但是密度降低, 说明静水持 留时间过长不利于盐地风毛菊在水平空间上的拓展。

\section{2 盐地风毛菊叶性状和光合、苂光特征}

如表3所示, 随着静水持留时间的增加，盐地风 毛菊的 $L A 、 S L A$ 和 $L D W$ 均呈增加趋势, 分别增加了 1.47、0.75和 0.41 倍; 而 $L T 、 C_{\mathrm{a}} 、 C_{\mathrm{b}}$ 和 $C_{\mathrm{car}}$ 呈减小趋 势，减少了 $33 \% 、 77 \% 、 65 \%$ 和 $58 \% ; P_{\mathrm{n}} 、 T_{\mathrm{r}}$ 和 $W U E$ 呈先增加后减少的趋势，整体上分别减少了 $19 \%$ 、 $10 \%$ 和 $10 \% ; Y(I I) 、 Y(N O)$ 和 $E T R$ 均呈减少的趋势，分 别减少了 $30 \% 、 39 \%$ 和 $18 \% ; Q P$ 呈先增加后减少的趋 势，整体减少了 $29 \% ; N P Q 、 Y(N P Q)$ 均呈增加趋势,

表3 小苏干湖盐沼湿地盐地风毛菊叶性状与光合生理参数特征(平均值 土标准误差)

Table 3 Leaf traits characteristics and photosynthetic physiological parameters of Saussurea salsa in salt marshes of Xiao Sugan Lake (mean $\pm S E$ )

\begin{tabular}{lccc}
\hline 参数 Parameter & \multicolumn{3}{c}{ 样地 Plot } \\
\cline { 2 - 4 } & $\mathrm{I}$ & $\mathrm{II}$ & $\mathrm{III}$ \\
\hline$L A\left(\mathrm{~cm}^{2}\right)$ & $7.14 \pm 0.36^{\mathrm{c}}$ & $8.34 \pm 0.42^{\mathrm{b}}$ & $17.61 \pm 0.88^{\mathrm{a}}$ \\
$L T(\mathrm{~mm})$ & $0.15 \pm 0.01^{\mathrm{a}}$ & $0.14 \pm 0.01^{\mathrm{a}}$ & $0.10 \pm 0.01^{\mathrm{b}}$ \\
$S L A\left(\mathrm{~cm}^{2} \cdot \mathrm{g}^{-1}\right)$ & $8.28 \pm 0.41^{\mathrm{b}}$ & $8.82 \pm 0.44^{\mathrm{b}}$ & $14.53 \pm 0.73^{\mathrm{a}}$ \\
$L D W(\mathrm{~g})$ & $0.86 \pm 0.04^{\mathrm{a}}$ & $0.95 \pm 0.05^{\mathrm{a}}$ & $1.21 \pm 0.06^{\mathrm{b}}$ \\
$C_{\mathrm{a}}\left(\mathrm{mg} \cdot \mathrm{g}^{-1}\right)$ & $5.39 \pm 0.27^{\mathrm{a}}$ & $3.11 \pm 0.16^{\mathrm{b}}$ & $1.26 \pm 0.06^{\mathrm{c}}$ \\
$C_{\mathrm{b}}\left(\mathrm{mg} \cdot \mathrm{g}^{-1}\right)$ & $1.93 \pm 0.10^{\mathrm{a}}$ & $1.15 \pm 0.06^{\mathrm{b}}$ & $0.67 \pm 0.03^{\mathrm{c}}$ \\
$C_{\mathrm{car}}\left(\mathrm{mg} \cdot \mathrm{g}^{-1}\right)$ & $1.39 \pm 0.07^{\mathrm{a}}$ & $0.67 \pm 0.03^{\mathrm{b}}$ & $0.58 \pm 0.03^{\mathrm{c}}$ \\
$P_{\mathrm{n}}\left(\mu \mathrm{mol} \mathrm{CO}{ }_{2} \cdot \mathrm{m}^{-2} \cdot \mathrm{s}^{-1}\right)$ & $4.67 \pm 0.23^{\mathrm{b}}$ & $5.17 \pm 0.26^{\mathrm{a}}$ & $3.77 \pm 0.19^{\mathrm{c}}$ \\
$T_{\mathrm{r}}\left(\mathrm{mmol} \mathrm{H} \mathrm{O} \cdot \mathrm{m}^{-2} \cdot \mathrm{s}^{-1}\right)$ & $1.08 \pm 0.05^{\mathrm{a}}$ & $1.19 \pm 0.06^{\mathrm{a}}$ & $0.97 \pm 0.05^{\mathrm{b}}$ \\
$W U E\left(\mu \mathrm{mol} \mathrm{CO} \cdot \mathrm{mmol}^{-1} \mathrm{H}_{2} \mathrm{O}\right)$ & $4.32 \pm 0.22^{\mathrm{a}}$ & $4.34 \pm 0.22^{\mathrm{a}}$ & $3.89 \pm 0.19^{\mathrm{b}}$ \\
$Y(I I)$ & $0.33 \pm 0.02^{\mathrm{a}}$ & $0.33 \pm 0.02^{\mathrm{a}}$ & $0.23 \pm 0.01^{\mathrm{b}}$ \\
$Y(N O)$ & $0.38 \pm 0.02^{\mathrm{a}}$ & $0.26 \pm 0.01^{\mathrm{b}}$ & $0.23 \pm 0.01^{\mathrm{c}}$ \\
$Y(N P Q)$ & $0.29 \pm 0.01^{\mathrm{c}}$ & $0.41 \pm 0.02^{\mathrm{b}}$ & $0.54 \pm 0.03^{\mathrm{a}}$ \\
$Q P$ & $0.73 \pm 0.04^{\mathrm{a}}$ & $0.75 \pm 0.04^{\mathrm{a}}$ & $0.52 \pm 0.03^{\mathrm{b}}$ \\
$N P Q$ & $0.19 \pm 0.01^{\mathrm{c}}$ & $0.40 \pm 0.02^{\mathrm{b}}$ & $0.59 \pm 0.03^{\mathrm{a}}$ \\
$E T R\left(\mu \mathrm{mol} \cdot \mathrm{m}^{-2} \cdot \mathrm{s}^{-1}\right)$ & $60.02 \pm 3.00^{\mathrm{a}}$ & $51.94 \pm 2.60^{\mathrm{b}}$ & $49.02 \pm 2.45^{\mathrm{c}}$ \\
\hline
\end{tabular}

同行不同小写字母表示样地间差异显著 $(p<0.05)$ 。参数同表 1 。

Different lowercase letters in the same row indicate significant differences among plots $(p<0.05)$. Parameters see Table 1 .
分别增加了 2.1 和 0.86 倍。盐地风毛菊叶片性状和光 合、苂光特性随着静水时空演变格局的变化呈现明 显的规律性变化，表明静水持留时间过长不利于盐 地风毛菊叶片叶绿素及类胡夢卜素的合成和光合作 用的进行，盐地风毛菊叶片适时调整叶片构型构建 和PSII天线色素吸收光能的分配，实现叶片光合产 物积累与耗散间的平衡, 这是盐沼湿地植物为适应 环境在外在结构和内在生理方面协同变异的结果。

\section{3 盐地风毛菊各功能性状与环境的RDA排序}

运用Canoco 4.5 软件对研究区盐地风毛菊叶片 形态性状和光合生理特征进行典范对应分析, 得到 排序轴与环境因子的关系以及各排序轴的特征值 (表4)。特征值分别为 0.5330 和 0.0500 , 功能性状与 环境因子的相关性分别为 0.9770 和 0.5650 , 排序轴 1 和 2 分别解释了功能性状与环境因子关系 $89.70 \%$ 和 $97.80 \%$ 的生态信息, 表明排序轴 1 和轴 2 均包含大 部分排序信息。因此采用第1轴和第2轴的信息对样 地的环境和植物功能性状与环境因子之间的关系进 行分析。

在排序图(图2)中, 每个蓝色箭头都表示一种植 物功能性状, 每个红色箭头都指示一种环境因子, 红色箭头与原点连线代表该环境因子对植物功能性 状的影响大小, 连线越长, 影响程度越大; 箭头与 排序轴所成的夹角大小则显示出该环境因子与排序 轴之间的相关性, 角度越小, 相关性越大(叶诺楠等, 2017)。综合表 4 和图 2 可知, 土壤电导率 $(E C)$ 是与第 一轴相关性最高的因子, 其次是土壤含水量 $(S M C)$ 和静水持留时间 $(T)$, 相关性分别为 $-0.9632,0.9366$ 和 0.9103 。

排序图(图2)显示, $T$ 和 $S M C$ 随RDA的第1轴从左 向右逐渐增大, $E C$ 则随着第 1 排序轴由左向右逐渐 减小。位于第1轴右侧的功能性状 $L D W 、 L A 、 S L A$ 、 $Y(N P Q) 、 N P Q$ 主要受 $T$ 和 $S M C$ 的影响; 而 $L T 、 C_{\mathrm{a}}$ 、 $C_{\mathrm{b}} 、 C_{\mathrm{car}} 、 P_{\mathrm{n}} 、 T_{\mathrm{r}} 、 W U E 、 Y(N O) 、 Y(I I) 、 Q P$ 等主要 
表4 小苏干湖盐沼湿地盐地风毛菊功能性状与环境因子的㝋余分析排序结果

Table 4 Redundancy analysis analysis results of functional traits and environmental factors of Saussurea salsa in salt marshes of Xiao Sugan Lake

\begin{tabular}{|c|c|c|c|c|}
\hline 统计量 Statistic & & 轴1 Axis 1 & 轴2 Axis 2 & 总方差 Total variance \\
\hline 土壤含水量 Soil moisture content & & 0.9366 & 0.0389 & 1.0000 \\
\hline 土壤电导率 Soil electrical conductivity & & -0.9632 & -0.0524 & \\
\hline 静水持留时间 Water-logging duration & & 0.9103 & 0.1988 & \\
\hline 特征值 Eigenvalues & & 0.5330 & 0.0500 & \\
\hline $\begin{array}{l}\text { 功能性状与环境的相关性 } \\
\text { Function traits-environment correlations }\end{array}$ & & 0.9770 & 0.5650 & \\
\hline $\begin{array}{l}\text { 累积百分比方差 } \\
\text { Explained variation (cumulative) }\end{array}$ & $\begin{array}{l}\text { 功能性状数据 } \\
\text { Function traits data }\end{array}$ & 55.3000 & 60.2000 & \\
\hline & $\begin{array}{l}\text { 功能性状-环境关系 } \\
\text { Relationship between function traits and environment relation }\end{array}$ & 89.7000 & 97.8000 & \\
\hline 总特征值 All eigenvalues & & & & 1.0000 \\
\hline 总典范特征值 Canonical eigenvalues & & & & 0.6160 \\
\hline
\end{tabular}

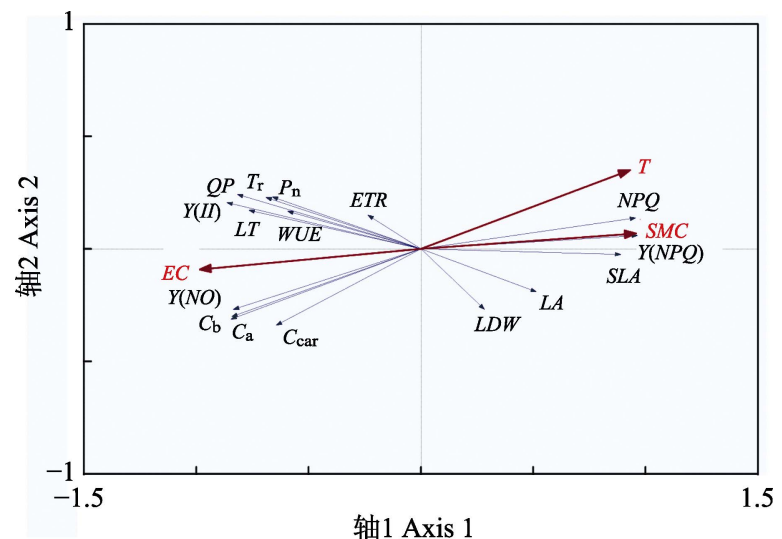

图 2 小苏干湖盐沼湿地盐地风毛菊功能性状与环境因子的 圥余分析。参数同表 1 。 $T$, 静水持留时间。

Fig. 2 Redundancy analysis ordination of functional traits and environmental factors of Saussurea salsa in salt marshes of Xiao Sugan Lake. Parameters see Table 1. T, water-logging duration.

受 $E C$ 的影响, 且与 $T$ 和 $S M C$ 负相关。盐地风毛菊叶 片的 $E T R$ 位于排序轴的中心位置, 表明 $E T R$ 受环境 因子的影响较小。其中 $S L A 、 Y(N P Q) 、 N P Q 、 C_{\mathrm{a}}$ 、
$C_{\mathrm{b}} 、 Y(N O) 、 Y(I I) 、 Q P$ 受环境因子的影响较大。

\section{4 盐地风毛菊各功能性状与环境因子的协方差} 分析

对RDA排序获得受环境因子影响较大的各功 能性状进行协变量剔除的协方差分析, 结果(表5)表 明, $S L A 、 C_{\mathrm{a}} 、 C_{\mathrm{b}} 、 Y(N P Q) 、 N P Q 、 Y(N O) 、 Y(I I)$ 、 $Q P$ 均与实验设计的水淹梯度有极显著相关关系 $(p<$ $0.005)$ 。

\section{5 盐地风毛菊叶性状和叶绿素荧光参数相关性 分析}

协方差分析所得与淹水梯度最相关的盐地风毛 菊的主要叶性状和光合生理特征的相关性如表6所 示, Perason相关分析结果表明，盐地风毛菊叶片的 $C_{\mathrm{a}}$ 和 $C_{\mathrm{b}}$ 仅与 $Y(N O)$ 呈显著正相关关系; $S L A$ 与 $Y(I I)$ 和 $Q P$ 均呈极显著的负相关关系 $(p<0.01) ;$ 与 $Y(N P Q)$ 呈极显著的正相关关系 $(p<0.01)$, 与 $N P Q$ 呈极显著 正相关关系。结果表明, 湿地群落不同水淹梯度的

表5 小苏干湖盐地风毛菊功能性状与环境因子的协方差分析(平均值土标准误差)

Table 5 Covariance analysis between functional traits and environmental factors of Saussurea salsa in salt marshes of Xiao Sugan Lake (mean \pm SE)

\begin{tabular}{|c|c|c|c|c|c|c|c|c|c|c|}
\hline $\begin{array}{l}\text { 功能性状 } \\
\text { Functional traits }\end{array}$ & $\begin{array}{c}\text { 总离差平方和 } \\
S S T \\
S T\end{array}$ & $\begin{array}{c}\text { 残差均方 } \\
M S E\end{array}$ & $\begin{array}{c}\text { 未考虑协变量 } \\
\text { 的均方 } M S_{1}\end{array}$ & $F_{1}\left(M S_{1} / M S E\right)$ & $\begin{array}{c}\text { 显著性水平 } \\
p_{1}\end{array}$ & $\begin{array}{c}\text { 判定系数 } \\
R_{1}^{2}\end{array}$ & $\begin{array}{l}\text { 考虑协变量 } \\
\text { 的均方 } M S_{2}\end{array}$ & $F_{2}\left(M S_{2} / M S E\right)$ & $\begin{array}{c}\text { 显著性水平 } \\
p_{2}\end{array}$ & $\begin{array}{c}\text { 判定系数 } \\
R_{2}^{2}\end{array}$ \\
\hline SLA & 6.3111 & 2.1295 & 3.1556 & 1.4819 & 0.2660 & 0.8520 & 29.4255 & 13.8183 & 0.0001 & 0.7900 \\
\hline$C_{\mathrm{a}}$ & 4.4327 & 0.5722 & 2.2163 & 3.8733 & 0.0504 & 0.8890 & 10.9506 & 19.1375 & 0.0000 & 0.8420 \\
\hline$C_{\mathrm{b}}$ & 0.3498 & 0.0804 & 0.1749 & 2.1754 & 0.1563 & 0.8540 & 1.1329 & 14.0905 & 0.0001 & 0.8790 \\
\hline$Y(I I)$ & 0.0046 & 0.0006 & 0.0023 & 4.1743 & 0.0421 & 0.8770 & 0.0094 & 17.0931 & 0.0000 & 0.8260 \\
\hline$Y(N P Q)$ & 0.0081 & 0.0004 & 0.0041 & 10.6622 & 0.0022 & 0.9770 & 0.0391 & 102.5328 & 0.0000 & 0.9680 \\
\hline$Y(N O)$ & 0.0160 & 0.0001 & 0.0080 & 136.0476 & 0.0000 & 0.9910 & 0.0152 & 259.0791 & 0.0000 & 0.9870 \\
\hline$Q P$ & 0.0247 & 0.0034 & 0.0124 & 3.5928 & 0.0599 & 0.8320 & 0.0410 & 11.9195 & 0.0003 & 0.7630 \\
\hline$N P Q$ & 0.0234 & 0.0005 & 0.0117 & 22.8254 & 0.0001 & 0.9870 & 0.0931 & 181.1783 & 0.0000 & 0.9810 \\
\hline
\end{tabular}

参数同表 1 。

$F, F$-test; $M S$, mean square; $M S E$, mean square for error; $p$, significance level; $R^{2}$, coefficient of determination; SST, sum of squares for total. Parameters see Table 1. 
表6 小苏干湖盐沼湿地盐地风毛菊叶性状和叶绿素苂光特征之间的相 关性分析

Table 6 Correlation analysis between leaf traits and chlorophyll fluorescence characteristics of Saussurea salsa in salt marshes of Xiao Sugan Lake

\begin{tabular}{lcccccccc}
\hline & $C_{\mathrm{a}}$ & $C_{\mathrm{b}}$ & $S L A$ & $Y(I I)$ & $Y(N P Q)$ & $Y(N O)$ & $N P Q$ & $Q P$ \\
\hline$C_{\mathrm{a}}$ & 1.00 & & & & & & & \\
$C_{\mathrm{b}}$ & $1.00^{* *}$ & 1.00 & & & & & & \\
$S L A$ & -0.14 & -0.18 & 1.00 & & & & & \\
$Y(I I)$ & 0.06 & 0.10 & $-1.00^{* *}$ & 1.00 & & & & \\
$Y(N P Q)$ & -0.53 & -0.57 & $0.91^{* *}$ & $-0.88^{*}$ & 1.00 & & & \\
$Y(N O)$ & $0.79^{*}$ & $0.82^{*}$ & -0.71 & 0.65 & $-0.94^{* *}$ & 1.00 & & \\
$N P Q$ & -0.58 & -0.61 & $0.89^{*}$ & $-0.85^{*}$ & $1.00^{* *}$ & $-0.95^{* *}$ & 1.00 & \\
$Q P$ & -0.02 & 0.02 & $-0.99^{* *}$ & $1.00^{* *}$ & $-0.84^{*}$ & 0.59 & $-0.81^{*}$ & 1.00
\end{tabular}

$*$, 在 0.05 水平上(双侧)显著相关; $* *$, 在 0.01 水平上(双侧)显著相关。参 数同表 1 。

*, significant at the 0.05 level (bilateral); **, significant at the 0.01 level (bilateral). Parameters see Table 1.

样地间, $S L A$ 与 $Y(I I) 、 Q P 、 Y(N P Q)$ 间均呈极显著相 关关系 $(p<0.01)$, 这些关系与叶片叶绿素苂光生理 特征密切相关, 是植物叶片叶功能性状对环境长期 适应的结果。

\section{6 各淹水程度下盐地风毛菊叶片中PSII量子产}

\section{量的转化}

不同静水持留时间下盐地风毛菊叶片中PSII量 子产量转化存在显著差异 $(p<0.05)$ (图3)。随着淹水 时间的增加，在盐地风毛菊叶片吸收光能一定的条 件下, PSII实际量子产量 $(Y(I I))$ 所占比例呈降低趋势, 调节性能量耗散的量子产额 $(Y(N P Q))$ 所占比例呈增 加趋势, 非调节性能量耗散的量子产额 $(Y(N O))$ 所 占比例呈降低的趋势。表明盐地风毛菊为适应胁迫 生境, 适时调整叶片吸收的光能在光合作用、热耗
散和叶绿素苂光三方面的分配比例, 实现植物叶片 对光能的积累与耗散之间的平衡。

\section{3 讨论}

叶性状是植物的重要特性之一(Cornelissen et al., 2003), 是叶片响应环境变化所形成的内在生理 及外在形态方面的适应对策，不仅与植物对资源的 获得、利用及利用效率密切相关，还能客观地反映 植物为了获得最大碳同化产物所采取的生存策略 (毛伟等, 2012)。本研究发现，随着静水持留时间的 增加, 样地盐地风毛菊形态上采取小 $S L A$ 的肉质化 小叶模式、光合生理上具有高 $Y(I I)$ 、低 $Y(N P Q)$ 的协 同变异适应高盐生境; 样地III则选择大 $S L A$ 的大叶 模式和低 $Y(I I)$ 、高 $Y(N P Q)$ 的协同变异策略适应长期 淹水生境; 3 个样地的盐地风毛菊 $S L A$ 与 $Y(I I)$ 和 $Q P$ 均 呈极显著负相关关系 $(p<0.01)$, 与 $Y(N P Q)$ 呈极显 著正相关关系 $(p<0.01), C_{\mathrm{a}}$ 和 $C_{\mathrm{b}}$ 仅与 $Y(N O)$ 呈显著 正相关关系 $(p<0.05)$ 。内陆盐沼湿地静水时空演变 格局的差异性导致湿地群落生存环境及资源异质性 分布，使植物通过调整自身叶片构型和内在生理生 态功能实现光合碳同化产物的收支平衡以适应特殊 生境, 体现了内陆盐沼湿地植物在严酷环境下较强 的环境耐受性和抗逆性。

\section{1 轻度淹水区盐地风毛菊叶形态性状与光合生 理特征对淹水的响应}

植物叶片暴露在环境中，是对环境变化最敏感 的部位，叶片表皮首先对环境的变化做出响应 (Campitelli \& Stinchcombe 2013; Adebowale et al.,
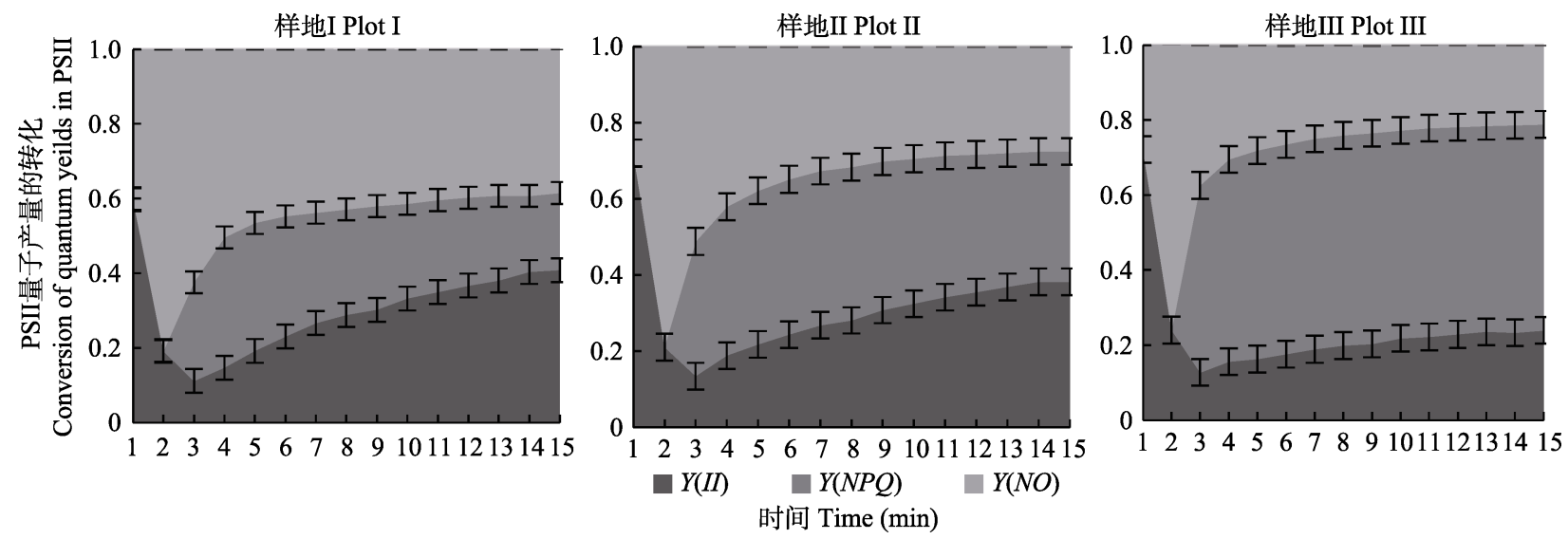

图3 不同淹水程度下盐地风毛菊叶片中光系统II (PSII)量子产量的转化(平均值沶准偏差)。 $Y(I I)$, PSII光化学量子产量; $Y(N P Q)$, 调节性能量耗散的量子产量; $Y(N O)$, 非调节性能量耗散的量子产量。光合有效辐射 $=1200 \mu \mathrm{mol} \cdot \mathrm{m}^{-2} \cdot \mathrm{s}^{-1}$ 。

Fig. 3 Conversion of quantum yields in photosynthetic system II (PSII) under different flooding gradient leaves of Saussurea salsa (mean $\pm S D)$. $Y(I I)$, photochemical quantum yields in PSII; $Y(N P Q)$, quantum yield of thermal dissipation used in regulatory energy dissipation; $Y(N O)$, the quantum yield of non-regulated energy dissipation. Photosynthetically active radiation $=1200 \mu \mathrm{mol} \cdot \mathrm{m}^{-2} \cdot \mathrm{s}^{-1}$. www.plant-ecology.com 
2014)。实验过程中发现, 在样地 I, 由于静水持留时 间最短使得该样地盐碱累积时间最长, 地表盐渍化 程度最强, 植被群落大多呈斑块状分布, 发育了盐 地风毛菊、海乳草和海非菜等大量耐盐和泌盐植物, 湿地群落平均高度 $(A H)$ 、平均密度 $(A D)$ 和土壤含水 量 $(S M C)$ 最小, 土壤电导率 $(E C)$ 和地上生物量 $(A B)$ 最大(表2)。耐盐性较好的盐地风毛菊成为该生境的 主要优势植物, 但由于该生境土壤盐分含量最大, 盐胁迫引起土壤水势降低, 诱导植物发生水分胁迫 (Kang \& Zhang, 2004; 李荣等, 2015), 加之样地I土 壤含水量最低(表2), 使盐地风毛菊面临水盐双重胁 迫，因而其高度和叶片干物质生物量最小(表2); 该 生境下盐地风毛菊形态上倾向于形成小而厚的肉质 化叶片, 低 $S L A$ 的小叶模式, 光合生理上具有高 $Y(I I) 、 Q P$ 和低 $Y(N P Q)$ 。主要原因有: (1)盐渍环境下, 盐地风毛菊叶片肉质化, 发育了大量贮水组织、栅 栏组织和输水组织, 一方面通过肉质化的叶细胞结 构冲淡细胞中盐离子浓度, 避免盐离子的毒害作用; 另一方面通过离子区域化作用增加液泡浓度, 降低 液泡水势, 缓解盐胁迫引起的水分胁迫(赵可夫等, 2013)。(2)在资源有限的条件下, 盐地风毛菊若增加 机械支撑则不利于其适应胁迫环境, 因此发育了高 度最低, $L A$ 和 $S L A$ 最小, $L T$ 最大的极端肉质化叶片 (表2, 表3); 厚叶可以通过增加蒸腾流从叶脉末端 到蒸发部位的路径长度来减缓水分损失(Brodribb \& Jordan, 2011; Scoffoni et al., 2011), 从而减少水分蒸 腾散失(Larcher, 1995), 提高叶片 $W U E$ 和光能利用 率, 使叶片获得较高的 $P_{\mathrm{n}}, Y(I I)$ 也较高(表3; 图3)。(3) 该样地高度肉质化的厚叶片能够容纳更多的叶绿体, 使得叶片叶绿素含量增加, 有利于胁迫生境下 ETR 的增加; 加之栅栏组织的增加, 能增大叶绿体对光 照和 $\mathrm{CO}_{2}$ 的吸收面积(魏志刚和王玉成, 2015), 因此, 该样地 $Y(I I)$ 和 $Q P$ 均较高(表3; 图3), $Y(N O)$ 所占比例 也较高, 在叶片吸收光能一定的条件下, $Y(N P Q)$ 所 占比例则最小(图3), $N P Q$ 也最小(表3)。实验中发现 盐地风毛菊叶片 $C_{\mathrm{a}} 、 C_{\mathrm{b}} 、 C_{\mathrm{car}}$ 和 $E T R$ 在样地 $\mathrm{I}$ 最大 $($ 表 $3)$, 盐地风毛菊通过选择小且厚的小叶片实现了较 高的 $E T R$ 和 $Y(I I)$, 在增加叶片光照利用能力和捕获 能力(王艺和韦小丽, 2010)的同时, 提高了胁迫生境 下叶片的自我保护能力(Liao et al., 2004)。因此, SLA 与 $Y(I I)$ 和 $Q P$ 均呈极显著负相关关系 $(p<0.01)$ (表 6$)$, 与 $Y(N P Q)$ 呈极显著正相关关系 $(p<0.01)$ (表 6$), C_{\mathrm{a}}$ 和
$C_{\mathrm{b}}$ 仅与 $Y(N O)$ 呈显著正相关关系 $(p<0.05)$ (表6)。表 明在轻度淹水区, 虽然土壤盐渍化程度高, 但对稀 盐盐生植物盐地风毛菊光合作用的进行并无显著的 抑制作用, 体现了盐沼湿地盐生植物长期适应胁迫 生境的耐受性和抗逆性策略。

\section{2 重度淹水区盐地风毛菊叶形态性状与光合生 理特征对淹水的响应}

光合作用是一种复杂的代谢途径, 需要精细的 调控才能对多变的自然环境做出反应(Sello et al., 2019), 光合效率表征植物对逆境的适应性和可塑 性(Kalaji et al., 2011; Sánchez et al., 2015)。在样地III, 由于静水持留时间最长, 水淹时间的增加使得该生 境盐碱累积时间与其他样地相比最少，土壤盐渍化 程度最低, 泌盐植物和稀盐植物逐渐退化, 发育了 赖草、海非菜等大量耐水淹植物, 仅有少量盐地风 毛菊, 因此湿地群落高度和 $S M C$ 最大, $E C$ 和 $A B$ 最小 (表2); 表明盐胁迫的进一步缓解不利于稀盐植物盐 地风毛菊在空间上的拓展。因此, 盐地风毛菊密度 最小, 高度最大(表2)。该生境下盐地风毛菊形态上 倾向于大 $S L A$ 的大叶模式, 光合生理上具有低 $Y(I I)$ 、 $Q P$ 和高 $Y(N P Q)$ 。主要原因有: (1)水淹时间的增加使 得该生境盐胁迫缓解的同时土壤水分过饱和，植物 根系缺氧, 耐水淹植物大量发育, 群落资源竞争加 剧, 在资源有限的条件下盐地风毛菊增加机械支撑 (表2), 形成了大而薄的大叶片(表3), 有利于增加叶 片补光面积, 扩大空气接触面(表3), 因而 $L D W$ 和 $S L A$ 最大(表 3); 大而薄的叶片能够使 $\mathrm{CO}_{2}$ 和水分等 从气孔到达叶绿体的路径缩短, 有利于光的透过和 光能的吸收(宋璐璐等, 2012), 进而提高盐地风毛菊 植株的生存适合度和群落竞争力; 另一方面植株间 的遮阴现象降低了叶片的 $T_{\mathrm{r}}$, 从而降低了叶片的 $P_{\mathrm{n}}$ 和 $W U E$ (表3), 使得风毛菊叶片 $Y(I I)$ 降低(表3; 图3), $Q P$ 表现为最小(表3)。(2)实验发现随着该样地盐胁 迫的改善, 耐水淹湿地植物的大量发育, 引起群落 中植被间的遮阴加剧, 使盐地风毛菊种群植株间产 生强烈的光竞争, 不利于叶片叶绿素和类胡萝卜素 的合成, 因此该样地叶绿素含量和 $C_{\mathrm{car}}$ 最少(表3), 盐地风毛菊叶片光能利用能力较样地 $\mathrm{I}$ 显著降低, 光化学活性和光合速率大大降低(王艺和韦小丽, 2010 ), 因而该样地叶片ETR最低(表3), $Y(I I)$ 和 $Y(N O)$ 所占比例最低(表3; 图3), 在叶片吸收光能一定的 条件下, $Y(N P Q)$ 所占比例则最大(图3), $N P Q$ 也最大 
(表3)。因此, 该样地 $S L A$ 与 $Y(I I)$ 和 $Q P$ 均呈极显著负 相关关系 $(p<0.01)$ (表 6$)$, 与 $Y(N P Q)$ 呈极显著正相 关关系 $(p<0.01)$ (表 6$), C_{\mathrm{a}}$ 和 $C_{\mathrm{b}}$ 仅与 $Y(N O)$ 呈显著正 相关关系 $(p<0.05)$ (表 6$)$ 。表明随着盐胁迫的进一步 改善, 盐地风毛菊适时调整叶片构型构建实现了对 有限光资源的有效利用, 体现了盐沼湿地植被较强 的叶片可塑性机制和环境耐受性。

植物通过改变形态特性和生理代谢来适应环境 的变化(Gong et al., 2011)。在样地II, 由于该生境静 水持留时间, 地表盐碱累积强度均处于样地 $\mathrm{I}$ 和样 地III之间，因而湿地群落的 $S M C 、 E C 、 A H 、 A B$ 和 盐地风毛菊种群的高度处于样地I和III之间(表2); 由于土壤水盐对盐地风毛菊的胁迫均有所缓解, 因 而盐地风毛菊植株密度最大(表2)。在资源有限的条 件下, 盐地风毛菊选择了适中的 $L A 、 L T 、 S L A$ 和机 械支撑结构(表2, 表3), 叶绿素含量和 $C_{\mathrm{car}}$ 均居中(表 $3)$, 从而实现了叶片对光能利用和截获能力的最大 化, 因而该样地叶片 $P_{\mathrm{n}} 、 Q P$ 最大(表3), $Y(I I)$ 与样地 $\mathrm{I}$ 无显著差异(表3)。这一方面是因为土壤盐碱累积较 样地I降低使得盐地风毛菊植株吸水阻力减少, 水 分条件较样地(I)有所改善; 另一方面, 由于该样地 植物受水淹胁迫与样地III相比相对较小, 因此该样 地叶片 $E T R$ 表现居中(表3)。此外, 在叶片吸收光能 一定的条件下, 光化学反应消耗的能量较样地 $\mathrm{I}$ 无 显著变化, $Y(N O)$ 有所降低, $Y(N P Q)$ 增加(表3; 图3), 这可能是因为虽然 $S M C$ 增加和 $E C$ 降低使得水盐胁 迫较样地I有所缓解, 但盐地风毛菊叶片光合活性 与样地 $\mathrm{I}$ 无显著差异所致; 所以 $Y(I I)$ 较样地 $\mathrm{I}$ 无明显 变化, 但由于叶片叶绿素含量和 $C_{\mathrm{car}}$ 的下降(表3), 导致叶片ETR降低, 为使资源利用最有效, 盐地风 毛菊形态上采取适中叶片模式, 光合生理上具有适 中 $Y(I I) 、 Y(N P Q)$ 和高 $Q P$ 。因而, $S L A$ 与 $Y(I I)$ 和 $Q P$ 均 呈极显著负相关关系 $(p<0.01)$ (表6), 与 $Y(N P Q)$ 呈 极显著正相关关系 $(p<0.01)$ (表6), $C_{\mathrm{a}}$ 和 $C_{\mathrm{b}}$ 仅与 $Y(N O)$ 呈显著正相关关系 $(p<0.05)$ (表6), 这体现了内陆盐 沼湿地植物随环境条件的改变, 适时调整自身叶片形 态特征实现叶片光合碳同化产物的收支平衡, 维持 自身在严酷环境下的正常的生长和繁殖的生存策略。

\section{4 结论}

植物叶形态性状与光合生理特征对淹水的响应 分析能反映植物在长期严酷生境下形成的光合作用
机理和环境抗逆性生存机制。在静水时空演变格局 差异条件下, 重度淹水区盐地风毛菊形态上采用小 $S L A$ 的肉质化小叶模式, 光合生理上具有高 $Y(I I)$ 和 低 $Y(N P Q)$ 的协同变异; 轻度淹水区则采用完全相反 的协同变异策略以实现植物叶片光合碳同化产物的 收支平衡, 体现了盐沼湿地植物在严酷环境下较强 的可塑性和耐受性机制, 这是盐沼湿地稀盐盐生植 物对自然环境长期适应形成的特殊生存策略。本研 究仅从静水持留时间、土壤含水量和土壤盐分的角 度出发, 通过分析叶性状、光合和叶绿素苂光在形 态和生理上的协同变异, 探讨了植物叶片形态与光 合生理特征对淹水的响应, 植物对淹水的响应是一 个复杂的生理过程, 叶片形态与光合生理的协同变 异还可能与植物分布格局、光照环境及其他构型构 建有关, 需要进一步探讨和研究。

\section{参考文献}

Adebowale A, Naidoo Y, Lamb J, Nicholas A (2014). Comparative foliar epidermal micromorphology of Southern African Strychnos L. (Loganiaceae): Taxonomic, ecological and cytological considerations. Plant Systematics and Evolution, 300, 127-138.

Bai XF, Bu QM, Tan YQ, Zhu JJ, Liu LD (2012). Effect of $\mathrm{NaCl}$ on photosynthesis and water status in arrowleaf saltbush under osmotic stress. Chinese Bulletin of Botany, 47, 500-507. [柏新富, 卜庆梅, 谭永芹, 朱建军, 刘林 德 (2012). $\mathrm{NaCl}$ 对渗透胁迫下三角叶滨藜光合作用和 水分状况的调节. 植物学报, 47, 500-507.]

Brodribb TJ, Jordan GJ (2011). Water supply and demand remain balanced during leaf acclimation of Nothofagus cunninghamii trees. New Phytologist, 192, 437-448.

Campitelli BE, Stinchcombe JR (2013). Natural selection maintains a single-locus leaf shape cline in ivyleaf morning glory, Ipomoea hederacea. Molecular Ecology, 22, $552-564$.

Cornelissen JHC, Lavorel S, Garnier E, Díaz S, Buchmann N, Gurvich DE, Reich PB, ter Steege H, Morgan HD, van der Heijden MGA, Pausas JG, Poorter H (2003). A handbook of protocols for standardised and easy measurement of plant functional traits worldwide. Australian Journal of Botany, 51, 335-380.

di Bella CE, Striker GG, Escaray FJ, Lattanzi FA, Rodríguez AM, Grimoldi AA (2014). Saline tidal flooding effects on Spartina densiflora plants from different positions of the salt marsh. Diversities and similarities on growth, anatomical and physiological responses. Environmental and Experimental Botany, 102, 27-36.

Gao Y, Xia JB, Chen YP, Zhao YY, Kong QX, Lang Y (2017).

www.plant-ecology.com 
Effects of extreme soil water stress on photosynthetic efficiency and water consumption characteristics of Tamarix chinensis in China's Yellow River Delta. Journal of Forestry Research, 28, 491-501.

Gimeno V, Syvertsen JP, Simón I, Nieves M, Díaz-López L, Martínez V, García-Sánchez F (2012). Physiological and morphological responses to flooding with fresh or saline water in Jatropha curcas. Environmental and Experimental Botany, 78, 47-55.

Gong CM, Bai J, Deng JM, Wang GX, Liu XP (2011). Leaf anatomy and photosynthetic carbon metabolic characteristics in Phragmites communis in different soil water availability. Plant Ecology, 212, 675-687.

Jin Y, Wang CK (2015). Trade-offs between plant leaf hydraulic and economic traits. Chinese Journal of Plant Ecology, 39, 1021-1032. [金鹰, 王传宽 (2015). 植物叶片水力与 经济性状权衡关系的研究进展. 植物生态学报, 39, 1021-1032.]

Kalaji HM, Govindjee, Bosa K, Kościelniak J, ŻukGołaszewska K (2011). Effects of salt stress on photosystem II efficiency and $\mathrm{CO}_{2}$ assimilation of two Syrian barley landraces. Environmental and Experimental Botany, $73,64-72$.

Kang SZ, Zhang JH (2004). Controlled alternate partial rootzone irrigation: Its physiological consequences and impact on water use efficiency. Journal of Experimental Botany, 55, 2437-2446.

Larcher W (1995). Physiological Plant Ecology: Ecophysiology and Stress Physiology of Functional Groups. 3rd ed. SpringerVerlag, New York, Berlin.

Li Q, Zhao CZ, Yao WX, Wang JL, Zhang WT (2018). The relationship between transpiration rate and leaf traits of Phragmites australis in response to soil moisture in Zhangye wetland. Chinese Journal of Ecology, 37, 1095-1101. [李群, 赵成章, 姚文秀, 王建良, 张伟涛 (2018). 张掖 湿地芦苇蒸腾速率与叶性状关系对土壤水分的响应. 生态学杂志, 37, 1095-1101.]

Li Q, Zhao CZ, Zhao LC, Wang JL, Zhang WT, Yao WX (2017). Empirical relationship between specific leaf area and thermal dissipation of Phragmites australis in salt marshes of Qinwangchuan. Chinese Journal of Plant Ecology，41，985-994. [李群, 赵成章, 赵连春, 王建良, 张 伟涛, 姚文秀 (2017). 秦王川盐沼湿地芦苇比叶面积与 叶片热耗散的关联性分析. 植物生态学报, 41, 985-994.]

Li R, Jiang ZM, Zhang SX, Cai J (2015). A review of new research progress on the vulnerability of xylem embolism of woody plants. Chinese Journal of Plant Ecology, 39, 838-848. [李荣, 姜在民, 张硕新, 蔡靖 (2015). 木本植 物木质部栓塞脆弱性研究新进展. 植物生态学报, 39, 838-848.]

Liao FY, Li HM, He P (2004). Effect of high irradiance and high temperature on chloroplast composition and structure of Dioscorea zingiberensis. Photosynthetica, 42, 487-492.

Liu X, Li LM, Li MJ, Su LC, Lian SM, Zhang BH, Li XY, Ge K, Li L (2018). AhGLK1 affects chlorophyll biosynthesis and photosynthesis in peanut leaves during recovery from drought. Scientific Reports, 8, 2250. DOI: 10.1038/ s41598-018-20542-7.

Mao W, Li YL, Zhang TH, Zhao XY, Huang YX, Song LL (2012). Research advances of plant leaf traits at different ecology scales. Journal of Desert Research, 32(1), 33-41. [毛伟, 李玉霖, 张铜会, 赵学勇, 黄迎新, 宋琳琳 (2012). 不同尺度生态学中植物叶性状研究概述. 中国 沙漠, 32(1), 33-41.]

Maxwell K, Johnson GN (2000). Chlorophyll fluorescence-A practical guide. Journal of Experimental Botany, 51, 659-668.

Milla R, Reich PB (2007). The scaling of leaf area and mass: The cost of light interception increases with leaf size. Proceedings of the Royal Society B: Biological Sciences, 274, 2109-2115.

Ogburn RM, Edwards EJ (2012). Quantifying succulence: A rapid, physiologically meaningful metric of plant water storage. Plant, Cell \& Environment, 35, 1533-1542.

Sánchez E, Scordia D, Lino G, Arias C, Cosentino SL, Nogués S (2015). Salinity and water stress effects on biomass production in different Arundo donax L. clones. BioEnergy Research, 8, 1461-1479.

Schreiber U (2004). Pulse-amplitude-modulation (PAM) fluorometry and saturation pulse method: An overview. In: Papageorgiou GC, Govindjee eds. Chlorophyll a Fluorescence. Springer, Dordrecht, Netherlands. 279-319.

Schreiber U, Bilger W, Neubauer C (1994). Chlorophyll fluorescence as a nonintrusive indicator for rapid assessment of in vivo photosynthesis. In: Schulze ED, Caldwell MM eds. Ecophysiology of Photosynthesis. Springer-Verlag, Berlin. 49-70.

Scoffoni C, Rawls M, McKown A, Cochard H, Sack L (2011). Decline of leaf hydraulic conductance with dehydration: Relationship to leaf size and venation architecture. Plant Physiology, 156, 832-843.

Sello S, Meneghesso A, Alboresi A, Baldan B, Morosinotto T (2019). Plant biodiversity and regulation of photosynthesis in the natural environment. Planta, 249, 1217-1228.

Shi SB, Shang YX, Shi R, Zhang B (2012). Responses of PSII photochemistry efficiency and photosynthetic pigments of Saussurea superba to short-term UV-B-supplementation. Chinese Journal of Plant Ecology, 36, 420-430. [师生波, 尚艳霞, 师瑞, 张波 (2012). 高山植物美丽风毛菊PSII 光化学效率和光合色素对短期增补UV-B辐射的响应. 植物生态学报, 36, 420-430.]

Song LL, Fan JW, Wu SH, Zhong HP, Wang N (2012). Response characteristics of leaf traits of common species 
along an altitudinal gradient in Hongchiba Grassland, Chongqing. Acta Ecologica Sinica, 32, 2759-2767. [宋璐 璐, 禁江文, 吴绍洪, 钟华平, 王宁 (2012). 红池坝草 地常见物种叶片性状沿海拔梯度的响应特征. 生态学 报, 32, 2759-2767.]

van den Brink FWB, van der Velde G, Bosman WW, Coops H (1995). Effects of substrate parameters on growth responses of eight helophyte species in relation to flooding. Aquatic Botany, 50, 79-97.

Wang T, Hu JT, Wang RQ, Liu CH, Yu D (2018). Tolerance and resistance facilitate the invasion success of Alternanthera philoxeroides in disturbed habitats: A reconsideration of the disturbance hypothesis in the light of phenotypic variation. Environmental and Experimental Botany, $153,135-142$.

Wang XK (2006). Principles and Techniques of Plant Physiological and Biochemical Experiments. 2nd edn. Higher Education Press, Beijing. 134-136. [王学奎 (2006). 植物 生理生化实验原理和技术(第2版). 高等教育出版社, 北 京. 134-136.]

Wang Y, Wei XL (2010). Advance on the effects of different light environments on growth, physiological biochemistry and morphostructure of plant. Journal of Mountain Agriculture and Biology, 29, 353-359, 370. [王艺, 韦小丽 (2010). 不同光照对植物生长、生理生化和形态结构影 响的研究进展. 山地农业生物学报, 29, 353-359, 370.]

Wang YF, Liu QQ, Pei ZY, Li HY (2012). Correlation between altitude and reproductive allocation in three Saussurea species on China's Qinghai-Tibetan Plateau. Chinese Journal of Plant Ecology, 36, 39-46. [王一峰, 刘启茜, 裴泽宇, 李海燕 (2012). 青藏高原3 种风毛菊属植物的 繁殖分配与海拔高度的相关性. 植物生态学报, 36, 39-46.]
Wei ZG, Wang YC (2015). The Corresponding Mechanisms of Plant Drought Stress. Science Press, Beijing. 8-11. [魏志 刚, 王玉成 (2015). 植物干旱胁迫响应机制. 科学出版 社, 北京. 8-11.]

Ye NN, Shen NP, Shang TQ, Gao HD, Guan JR, Yi LT (2017). Vegetation structure and internal relationship between distribution patterns of vegetation and environment in ecological service forest of Rui'an city in Zhejiang Province. Chinese Bulletin of Botany, 52, 496-510. [叶诺楠, 沈娜 娉, 商天其, 高洪娣, 管杰然, 伊力塔 (2017). 浙江瑞 安公益林群落结构及其与环境的相关性. 植物学报, 52 , 496-510. ]

Zhang HY, Xie BT, Duan WX, Dong SX, Wang BQ, Zhang LM, Shi CY (2018). Effects of drought stress at different growth stages on photosynthetic efficiency and water consumption characteristics in sweet potato. Chinese Journal of Applied Ecology, 29, 1943-1950. [张海燕, 解 备涛, 段文学, 董顺旭, 汪宝卿, 张立明, 史春余 (2018). 不同时期干旱胁迫对甘薯光合效率和耗水特性 的影响. 应用生态学报, 29, 1943-1950.]

Zhang YQ, Liang CZ, Wang W, Wang LX, Peng JT, Yan JC, Jia CZ (2010). Soil salinity and Achnatherum splendens distribution. Chinese Journal of Ecology, 29, 2438-2443. [张雅琼, 梁存柱, 王炜, 王立新, 彭江涛, 间建成, 贾 成朕 (2010). 芨芨草群落土壤盐分特征. 生态学杂志, 29, 2438-2443.]

Zhao KF, Li FZ, Zhang FS (2013). Chinese Halophytes. 2nd edn. Science Press, Beijing. 71-74. [赵可夫, 李法曾, 张 福锁 (2013). 中国盐生植物 (第二版). 科学出版社, 北 京. 71-74.]

责任编委: 储诚进 责任编辑: 李 敏 实习编辑: 赵 航 